\title{
PIEL DE TILAPIA: ¿AVANCE TECNOLÓGICO EN EL TRATAMIENTO DE QUEMADURAS?
}

\section{ARTÍCULO DE REVISIÓN}

CABRAL, Anna Julie Medeiros ${ }^{1}$, LIMA, Camila Araújo Novais², CRUZ FILHO, Eduardo Franco Correia ${ }^{3}$, SOARES, Gabriel Lucena de Carvalho ${ }^{4}$, ESPÍNOLA, Paulo Francisco Lucena de Araújo ${ }^{5}$, ALVES, Fernanda Araújo6 ${ }^{6}$, CRUZ, Ana Suzy de Góis Melo ${ }^{7}$

CABRAL, Anna Julie Medeiros. Et al. Piel de tilapia: ¿avance tecnológico en el tratamiento de quemaduras?. Revista Científica Multidisciplinar Núcleo do Conhecimento. Año. 06, Ed. 12, Vol. 05, págs. 50-64. Diciembre 2021. ISSN: 24480959, Enlace de acceso: https://www.nucleodoconhecimento.com.br/salud/piel-detilapia, DOI: 10.32749/nucleodoconhecimento.com.br/salud/piel-de-tilapia

\section{RESUMEN}

Introducción: La quemadura es una de las mayores agresiones que puede sufrir el cuerpo. El abordaje varía según el grado de la quemadura, desde el uso de clorhexidina, sulfadiazina de plata, desbridamiento de tejido necrótico, apósitos biosintéticos y pieles artificiales. Sin embargo, estos dos últimos tienen altos costos, por lo que han surgido varios estudios con el objetivo de buscar opciones más viables, como el uso de la piel de tilapia del Nilo en quemaduras, debido a sus propiedades curativas. Dicho esto, el presente artículo tiene como guía la pregunta:

\footnotetext{
${ }^{1}$ Estudiante del curso de Medicina del Centro Universitario de João Pessoa - UNIPÊ, João Pessoa - PB. ORCID: 0000-0002-5212-5521.

${ }^{2}$ Estudiante del curso de Medicina del Centro Universitario de João Pessoa - UNIPÊ, João Pessoa - PB. ORCID: 0000-0003-4609-4260.

${ }^{3}$ Estudiante del curso de Medicina del Centro Universitario de João Pessoa - UNIPÊ, João Pessoa - PB. ORCID: 0000-0001-6684-2161.

${ }^{4}$ Estudiante del curso de Medicina del Centro Universitario de João Pessoa - UNIPÊ, João Pessoa - PB. ORCID: 0000-0002-0618-4037.

${ }^{5}$ Estudiante del curso de Medicina del Centro Universitario de João Pessoa - UNIPÊ, João Pessoa - PB. ORCID: 0000-0001-7964-2118.

${ }^{6}$ Consejero. ORCID: 0000-0001-5235-5020.

${ }^{7}$ Consejero. ORCID: 0000-0002-0668-0540.
}

RC: 104335

Disponible: https://www.nucleodoconhecimento.com.br/salud/piel-de-tilapia 
¿Es este nuevo método, de hecho, un avance tecnológico tan importante para el tratamiento de pacientes quemados como parece? Objetivo: Analizar el uso de la piel de tilapia del Nilo en pacientes con lesiones por quemaduras, así como comparar con otras técnicas preestablecidas. Métodos: Se trata de una revisión bibliográfica integradora con un enfoque cualitativo. Los datos fueron recolectados a través de bases de datos PubMed y Biblioteca Virtual de Salud (BVS), de 2015 a 2020. Resultados: Los artículos indican un buen pronóstico para el uso de la piel de tilapia del Nilo en relación con las otras opciones vigentes para el tratamiento de quemaduras, con una ventaja significativa en la reducción del número de apósitos requeridos, para una mejor adherencia a la herida. Además, presenta características microscópicas similares a la piel humana, como alta resistencia a la tracción y extensión de rotura, reduciendo el tiempo de reepitelización y la intensidad del dolor, así como reduciendo los costos del tratamiento. Conclusión: A la vista de los hallazgos de la literatura reportada en la presente revisión, se concluye que los estudios con piel de tilapia del nilo demuestran ser una modalidad revolucionaria con beneficios en el tratamiento de pacientes con lesiones cutáneas superficiales y profundas. Por ello, los investigadores concluyeron, respondiendo a la pregunta guía, que el nuevo método supone, sí, un avance importante en el campo del tratamiento de quemaduras, porque se confirma su empleabilidad, además de demostrar una ventaja sobre algunas de las principales alternativas preexistentes.

Palabras clave: Tilapia, Quemaduras, Apósitos Biológicos.

\section{INTRODUCCIÓN}

La velocidad y el estilo de vida impuestos por la modernidad hacen que la incidencia del número de quemaduras aumente hoy en día. Mucho más allá de las lesiones físicas, las quemaduras también son responsables de problemas económicos asociados con daños irreparables a los pacientes y sus familias (HU et al., 2017). La quemadura es una de las mayores agresiones que puede sufrir el organismo humano, y se estima que en Brasil, hay alrededor de 1 millón de accidentes por quemaduras anualmente, según Leontsinis et al. (2018), ya sea un simple golpe de 
calor, quemaduras de primer grado, hasta la destrucción total de la piel (epidermis y dermis) y tejidos adyacentes, como en quemaduras de tercer grado (ALVES et al., 2015).

Cuando consideramos el tratamiento de quemaduras en Brasil, nos enfrentamos a dos realidades: la de la red pública y privada. En los centros de tratamiento de la red pública, la conducta seguida en relación a los apósitos en lesiones de segundo grado es el baño diario con clorhexidina al $2 \%$ y el apósito se realiza con el antimicrobiano tópico sulfadiazina de plata al 1\% hasta la reparación completa de la lesión; mientras que en las quemaduras de tercer grado, el tejido necrótico se desbrida en varias etapas, y luego se realiza el apósito con sulfadiazina de plata al $1 \%$ hasta que se prepara el lecho de la herida para el injerto. Por otro lado, en la red privada, teniendo en cuenta las diferentes condiciones financieras de cada paciente, se pueden utilizar apósitos biosintéticos y pieles artificiales, opciones importadas y de alto costo (ALVES et al., 2015).

Sin embargo, analizando la realidad vivida en Europa y Estados Unidos, el tratamiento a menudo implica el uso de pieles homólogas (haciendo uso de bancos de piel), heterólogo (de origen animal), apósitos biosintéticos y dermis artificiales (ALVES et al., 2015). En Brasil, todavía hay algunas confrontaciones para lograr la misma practicidad de estos otros países. Culturalmente, todavía existe una gran resistencia a la donación de piel, lo que termina limitando la disponibilidad del tejido para satisfacer la gran demanda. Además, tomando como referencia el Ministerio de Salud, para que Brasil pueda satisfacer la necesidad de piel homóloga para su uso en lesiones por quemaduras, sería necesario tener 13 bancos de piel distribuidos en todo el territorio nacional, sin embargo, sólo hay cinco (São Paulo, Curitiba, Río de Janeiro, Porto Alegre y Recife, que está discapacitado). Además de estas limitaciones, Brasil nunca ha tenido una piel animal registrada en la Agencia Nacional de Vigilancia Sanitaria (ANVISA) y puesta a disposición por el Sistema Único de Salud (SUS), que también termina restringiendo el uso de piel hertologosa en pacientes quemados (LEONTSINIS et al., 2018). 
Así, han surgido varios estudios con el objetivo de buscar apósitos para ser utilizados en pacientes quemados. Estos apósitos tienen como objetivo reducir los efectos de la contaminación sobre las lesiones, favorecer el proceso de cicatrización y ofrecer mejores resultados estéticos. Tener, idealmente, buena flexibilidad y adherencia a la cama, resistencia al estiramiento, fácil manejo, capacidad de supresión del dolor, bajo costo y fácil de obtener, así como previene pérdidas hidroelectrolíticas, contaminación bacteriana, favorece la epitelización de quemaduras y proporciona la formación de tejido de granulación adecuado.Una de las opciones es la búsqueda de sustitutos temporales de la piel y apósitos de materiales sintéticos o biosintéticos, debido a que reducen la frecuencia de cambio de apósito, sin embargo, los altos costos y su ineficacia para quemaduras profundas estimularon la búsqueda de materiales biológicos como alternativas viables (COSTA et al., 2019; MARCELO y BRANDT, 2019).

En este contexto, en 2011, el cirujano plástico Marcelo Borges, después de ver un artículo en el Jornal do Commercio de Pernambuco hablando sobre el uso de la piel de la especie Tilapia del Nilo (Oreochromis niloticus) en artesanías, uno de los peces más cultivados en Brasil, se le ocurrió por primera vez la idea de usar esta piel en el tratamiento de quemaduras. Pero solo en 2014, compartió la idea con el cirujano plástico de Ceará Edmar Maciel, y luego comenzó estudios sobre el uso de la piel de tilapia del Nilo en quemaduras. El investigador Odorico Moraes, presidente director del Centro de Investigación y Desarrollo de Medicamentos (NPDM), de la Universidad Federal de Ceará (UFC), y el cirujano plástico de Goiás Nelson Piccolo (LIMA JUNIOR et al.), también se integraron para conformar la coordinación del trabajo. 2017).

Según lo narrado por Lima Junior (2017), la piel de la tilapia del Nilo demuestra una epidermis recubierta con un epitelio de pavimento estratificado, seguido de extensas capas de colágeno. Gracias a su característica de guiar y definir la mayoría de los tejidos, se configura como un gran componente de los biomateriales, además de posibilitar la biodegradabilidad y biocompatibilidad, que favorecen su aplicación (LIMA JUNIOR, 2017; LIMA JUNIOR et al., 2019b, 2020b). 
Dicho esto, la pregunta correcta es: "¿Es este nuevo método, de hecho, un avance tecnológico tan importante para el tratamiento de pacientes quemados como parece ser?" El objetivo es, entonces, a través de este estudio, analizar si la piel de tilapia del nilo es una alternativa viable para ser utilizada en pacientes con lesiones por quemaduras, así como comparar con otras técnicas ya utilizadas, verificando las ventajas de la adopción de este nuevo método.

Más específicamente, este estudio tiene como objetivo evidenciar la buena ventaja del apósito cutáneo de tilapia en el tratamiento de quemaduras, correlacionando las propiedades físico-químicas de la tilapia con los beneficios del apósito y exponiendo la no inferioridad de los apósitos para la piel de tilapia en relación con otras soluciones en el mercado. Además de instigar la realización de más investigaciones científicas para obtener resultados más robustos sobre el tema.

\section{METODOLOGÍA}

Se refiere a una revisión integradora de la literatura, con un enfoque cualitativo, con propósito descriptivo de estudios nacionales e internacionales. Además, tiene un carácter aplicado, con el uso de un procedimiento bibliográfico para el análisis de los respectivos datos recolectados relacionados con el uso de piel de tilapia en pacientes quemados.

El presente estudio se realizó a través de la búsqueda de artículos a través del acceso a bases de datos pubmed y la Biblioteca Virtual en Salud (BVS). En un primer momento, se recogieron los descriptores relevantes para la temática seleccionada, siendo vocabulario de los Descriptores en Ciencias de la Salud (DeCS). Los términos elegidos fueron "Tilapia", "Quemaduras" y "Apósitos Biológicos" en los idiomas: portugués, inglés y español. Estos descriptores se asociaron con los operadores booleanos "OR" y "AND" elaborando la siguiente fórmula de investigación: "(Tilápia OR Tilapia OR Tilapia) AND (Queimaduras OR Burns OR Quemaduras) AND (Curativos Biológicos OR Biological Dressings OR Apósitos Biológicos)". 
Así, aplicando la lógica de la fórmula antes mencionada, se encontraron un total de 31 artículos en las bases de datos seleccionadas, 14 artículos publicados y 17 disponibles en la BVS. Los criterios de inclusión fueron: artículos disponibles en su totalidad, que retrataron el tema relacionado con la revisión integradora y artículos publicados e indexados en las bases de datos publicadas en los años 2015, 2016, 2017, 2018, 2019, 2020 y 2021, que presentaron el idioma en inglés, portugués y español. Además, los artículos que se duplicaron, no tenían contenido completo y que no cumplían con los objetivos de la investigación fueron excluidos de la revisión integradora.

La revisión bibliográfica integrativa no es práctica, por lo tanto, no requiere presentación al Comité de Ética en Investigación (CEP). Desde esta perspectiva, se elaboró una tabla mostrando la información principal de las bibliografías utilizadas, presentando los datos referentes al título, autores, año de publicación, país y los principales resultados de cada una.

\section{RESULTADOS}

Tabla 1: Uso de la piel de tilapia en quemaduras: bases teóricas e implicaciones prácticas.

\begin{tabular}{|l|l|l|l|}
\hline título & $\begin{array}{l}\text { Autores, } \\
\text { año de } \\
\text { publicación } \\
\text { y país }\end{array}$ & Resultados principales \\
\hline $\mathbf{A R T i ́ C U L O}$ & $\begin{array}{l}\text { Uso da pele de tilápia } \\
\text { (Oreochromis niloticus), } \\
\text { como curativo biológico } \\
\text { oclusivo, no tratamento de } \\
\text { queimaduras }\end{array}$ & $\begin{array}{l}\text { Lima Júnior } \\
\text { et al., 2017, }\end{array}$ & $\begin{array}{l}\text { El estudio mostró que la } \\
\text { piel de tilapia tiene una } \\
\text { adherencia considerable a } \\
\text { las heridas por } \\
\text { quemaduras en ratas de } \\
\text { prueba, con resultados } \\
\text { positivos durante la }\end{array}$ \\
\hline
\end{tabular}




\begin{tabular}{|c|c|c|c|}
\hline & & & $\begin{array}{l}\text { cicatrización, sin } \\
\text { mutaciones significativas } \\
\text { en los ámbitos bioquímico } \\
\text { y hematológico de la } \\
\text { función hepática y renal, } \\
\text { constituyendo una } \\
\text { posibilidad de apósito } \\
\text { biológico. }\end{array}$ \\
\hline $\begin{array}{l}\text { ARTÍ́CULO } \\
2\end{array}$ & $\begin{array}{l}\text { Xenoenxerto (pele da } \\
\text { Tilápia-do-Nilo) e hidrofibra } \\
\text { com prata no tratamento } \\
\text { das queimaduras de II grau } \\
\text { em adultos }\end{array}$ & $\begin{array}{l}\text { De Miranda } \\
\text { e Brandt, } \\
2019, \\
\text { Brasil }\end{array}$ & $\begin{array}{l}\text { La investigación mostró } \\
\text { que la tilapia del Nilo es } \\
\text { efectiva en la función de } \\
\text { apósito biológico oclusivo } \\
\text { en el tratamiento de } \\
\text { quemaduras de segundo } \\
\text { grado en adultos, con } \\
\text { medios similares en } \\
\text { cuanto al tiempo de } \\
\text { tratamiento, la referencia } \\
\text { del dolor y la necesidad de } \\
\text { reemplazo, con respecto } \\
\text { al manejo de pacientes } \\
\text { con Aquacel } A G \circledast \text {. }\end{array}$ \\
\hline $\begin{array}{l}\text { ARTÍ́CULO } \\
3\end{array}$ & $\begin{array}{l}\text { Avaliação microscópica, } \\
\text { estudo histoquímico e } \\
\text { análise de propriedades } \\
\text { tensiométricas da pele de } \\
\text { tilápia do Nilo }\end{array}$ & $\begin{array}{l}\text { Alves et al., } \\
2015 \text {, Brasil }\end{array}$ & $\begin{array}{l}\text { La piel de tilapia presenta } \\
\text { haces de fibras de } \\
\text { colágeno densas, } \\
\text { predominantemente tipo 1, } \\
\text { que presentan } \\
\text { características } \\
\text { microscópicas similares a } \\
\text { las de la piel humana, así } \\
\text { como una alta resistencia }\end{array}$ \\
\hline
\end{tabular}




\begin{tabular}{|c|c|c|c|}
\hline & & & $\begin{array}{l}\text { a la tracción y extensión a } \\
\text { la rotura, lo que la hace } \\
\text { prometedora como } \\
\text { biomaterial en medicina } \\
\text { regenerativa. }\end{array}$ \\
\hline $\begin{array}{l}\text { ARTÍCULO } \\
4\end{array}$ & $\begin{array}{l}\text { Innovative Burn Treatment } \\
\text { Using Tilapia Skin as a } \\
\text { Xenograft: A Phase II } \\
\text { Randomized Controlled } \\
\text { trial }\end{array}$ & $\begin{array}{l}\text { Lima Júnior } \\
\text { et al., 2020, } \\
\text { Brasil }\end{array}$ & $\begin{array}{lr}\text { El ensayo clínico } \\
\text { aleatorizado utilizó una } \\
\text { muestra de } \\
\text { participantes y demostró } \\
\text { que hubo una reducción } \\
\text { en: el tiempo de } \\
\text { reepitelización, } \\
\text { intensidad del dolor, la } \\
\text { cantidad } \\
\text { estética/analgésicos y la } \\
\text { necesidad de cambiar los } \\
\text { apósitos en comparación } \\
\text { con el grupo control, por lo } \\
\text { tanto, la piel de tilapia } \\
\text { presentó beneficios. }\end{array}$ \\
\hline $\begin{array}{l}\text { ARTÍCULO } \\
5\end{array}$ & $\begin{array}{l}\text { Tratamento } \\
\text { queimaduras de segundo } \\
\text { grau profundo em } \\
\text { abdômen, coxas e } \\
\text { genitália: uso da pele de } \\
\text { tilápia como um } \\
\text { xenoenxerto }\end{array}$ & $\begin{array}{l}\text { Lima Júnior } \\
\text { et al., 2020, } \\
\text { Brasil }\end{array}$ & $\begin{array}{l}\text { El caso clínico contribuyó } \\
\text { a reducir las limitaciones } \\
\text { relacionadas con el } \\
\text { acceso de áreas } \\
\text { anatómicas más } \\
\text { inaccesibles para su uso, } \\
\text { presentando buenos } \\
\text { resultados en la aplicación } \\
\text { en los genitales y la región } \\
\text { inguinal. Es una opción de } \\
\text { alta disponibilidad y }\end{array}$ \\
\hline
\end{tabular}




\begin{tabular}{|c|c|c|c|}
\hline & & & \\
\hline $\begin{array}{l}\text { ARTí́CULO } \\
6\end{array}$ & $\begin{array}{l}\text { Marine Collagen Peptides } \\
\text { from the Skin of Nile Tilapia } \\
\text { (Oreochromis niloticus): } \\
\text { Characterization and } \\
\text { Wound Healing Evaluation }\end{array}$ & $\begin{array}{l}\text { Zhang } \mathrm{Hu} \text { et } \\
\text { al., } 2017, \\
\text { China }\end{array}$ & $\begin{array}{l}\text { El ensayo de raspado in } \\
\text { vitro e in vivo reveló } \\
\text { consecuencias } \\
\text { significativas en el cierre } \\
\text { del raspado con piel de } \\
\text { tilapia, con evolución en el } \\
\text { proceso de curación por } \\
\text { escaldado de espesor } \\
\text { parcial profundo en los } \\
\text { conejos probados, } \\
\text { presentándose como un } \\
\text { tratamiento prometedor. }\end{array}$ \\
\hline $\begin{array}{l}\text { ARTÍCULO } \\
7\end{array}$ & $\begin{array}{l}\text { A Randomized Comparison } \\
\text { Study of Lyophilized Nile } \\
\text { Tilapia Skin and Silver- } \\
\text { Impregnated Sodium } \\
\text { Carboxymethylcellulose for } \\
\text { the Treatment of } \\
\text { Superficial Partial- } \\
\text { Thickness Burns }\end{array}$ & $\begin{array}{l}\text { Lima Júnior, } \\
\text { et al., 2020, } \\
\text { Brasil }\end{array}$ & $\begin{array}{l}\text { Este estudio piloto } \\
\text { demostró que no hay } \\
\text { inferioridad a la piel de } \\
\text { tilapia liofilizada como } \\
\text { opción terapéutica en } \\
\text { quemaduras, } \\
\text { comparación con el } \\
\text { apósito } \\
\text { carboximetilcelulosa } \\
\text { sórdida impregnado de } \\
\text { plata, con eficacia y } \\
\text { seguridad, lo que permite } \\
\text { el desarrollo de ensayos } \\
\text { clínicos aleatorios más } \\
\text { complejos en el futuro. }\end{array}$ \\
\hline $\begin{array}{l}\text { ARTÍ́CULO } \\
8\end{array}$ & $\begin{array}{lrr}\begin{array}{l}\text { Elaboração de } \\
\text { protocolo }\end{array} & \text { um } \\
\text { implementação } & & \text { para }\end{array}$ & $\begin{array}{l}\text { Leontsinis et } \\
\text { al., 2018, } \\
\text { Brasil }\end{array}$ & $\begin{array}{l}\text { El artículo reveló la } \\
\text { importancia de desarrollar } \\
\text { e implementar protocolos }\end{array}$ \\
\hline
\end{tabular}




\begin{tabular}{|c|c|c|c|}
\hline & $\begin{array}{l}\text { funcionamento do primeiro } \\
\text { banco de pele animal do } \\
\text { Brasil: Relato de } \\
\text { experiência }\end{array}$ & & $\begin{array}{l}\text { para el primer banco de } \\
\text { piel de animales acuáticos } \\
\text { del mundo, reforzando la } \\
\text { necesidad de establecer la } \\
\text { estandarización del } \\
\text { sistema. }\end{array}$ \\
\hline $\begin{array}{l}\text { ARTÍ́CULO } \\
9\end{array}$ & $\begin{array}{l}\text { Use of Tilapia Skin as a } \\
\text { Xenograft for Pediatric } \\
\text { Burn Treatment: A Case } \\
\text { Report }\end{array}$ & $\begin{array}{l}\text { Costa et al., } \\
2019, \\
\text { Estados } \\
\text { Unidos }\end{array}$ & $\begin{array}{l}\text { El xenoinjerto cutáneo de } \\
\text { tilapia en el caso de una } \\
\text { víctima de quemadura de } \\
3 \text { años mostró resultados } \\
\text { positivos con un impacto } \\
\text { social y financiero } \\
\text { significativo en el sistema } \\
\text { de salud. }\end{array}$ \\
\hline $\begin{array}{l}\text { ARTíCULO } \\
10\end{array}$ & $\begin{array}{l}\text { Innovative treatment using } \\
\text { tilapia skin as a xenograft } \\
\text { for partial thickness burns } \\
\text { after a gunpowder } \\
\text { explosion }\end{array}$ & $\begin{array}{l}\text { Lima Júnior } \\
\text { et al., 2019, } \\
\text { Inglaterra }\end{array}$ & $\begin{array}{l}\text { El informe del caso retrata } \\
\text { a un paciente masculino } \\
\text { de } 23 \text { años con } \\
\text { quemaduras superficiales } \\
\text { y profundas en la } \\
\text { extremidad superior } \\
\text { derecha e izquierda, } \\
\text { respectivamente. Con el } \\
\text { uso de piel de tilapia, la } \\
\text { reepitelización se realizó } \\
\text { en poco tiempo, sin } \\
\text { efectos secundarios y con } \\
\text { necesidad de cambio de } \\
\text { apósito. }\end{array}$ \\
\hline $\begin{array}{l}\text { ARTíCULO } \\
11\end{array}$ & $\begin{array}{l}\text { Pediatric Burn Treatment } \\
\text { Using Tilapia Skin as a } \\
\text { Xenograft for Superficial }\end{array}$ & $\begin{array}{l}\text { Lima Júnior, } \\
2020 \text {, } \\
\text { Inglaterra }\end{array}$ & $\begin{array}{l}\text { El uso de la piel de tilapia } \\
\text { se utilizó como un recurso } \\
\text { adicional junto con la }\end{array}$ \\
\hline
\end{tabular}


Partial-Thickness Wounds:

A Pilot Study

\section{ARTíCULO Comprehensive}

12
Assessment of Nile Tilapia

Skin

niloticus)

(Oreochromis

Hydrogels for Wound

Dressings sulfadiazina de plata. El estudio reveló que además de traer beneficios a los pacientes, disminuyó los costos del tratamiento, así como para los profesionales de la salud, como la reducción de la carga de trabajo.

$\mathrm{Ge}$ et al., El apósito de hidrogel de 2020, China colágeno mostró la promoción de la formación de capas epidérmicas y la maduración de los apéndices de la piel, demostrando ser un excelente nuevo apósito con eficacia en el manejo de quemaduras profundas.
ARTÍ́CULO 13
Tecnologias inovadoras: uso da pele da tilápia do Nilo no tratamento de queimaduras e feridas

$\begin{array}{ll}\text { 2017, Brasil } & \text { La piel de tilapia en } \\ & \text { quemaduras es una } \\ \text { patente brasileña, y el } & \text { objetivo de la } \\ & \text { investigación es el registro } \\ \text { de la piel en la Agencia } & \text { Nacional de Vigilancia } \\ \text { Sanitaria (ANVISA) y } \\ \text { puesta a disposición por el } \\ \text { Sistema Único de Salud } \\ \text { (SUS). }\end{array}$

Lima Júnior, La piel de tilapia en patente brasilena, $y$ el la investigación es el registro de la piel en la Agencia Nacional de Vigilancia Sanitaila (ANVISA) - y puesta a disposición por el (SUS). 


\begin{tabular}{|c|c|c|c|}
\hline $\begin{array}{l}\text { ARTÍCULO } \\
14\end{array}$ & $\begin{array}{l}\text { Chitosan hydrogel in } \\
\text { combination with marine } \\
\text { peptides from tilapia for } \\
\text { burns healing }\end{array}$ & $\begin{array}{l}\text { Ouyang et } \\
\text { al., 2018, } \\
\text { China }\end{array}$ & $\begin{array}{l}\text { Los péptidos marinos } \\
\text { extraídos de la tilapia } \\
\text { mostraron una } \\
\text { composición similar al } \\
\text { colágeno, además de una } \\
\text { importante actividad } \\
\text { antibacteriana. Presenta } \\
\text { una alta eficiencia curativa } \\
\text { y habilidades de migración } \\
\text { y proliferación celular en } \\
\text { comparación con el grupo } \\
\text { de control y otros } \\
\text { ungüentos disponibles en } \\
\text { la industria farmacéutica. }\end{array}$ \\
\hline
\end{tabular}

Fuente: Desarrollado por el autor (2021)

La revisión incluyó 14 artículos, entre los cuales, dos (14,3\%) informaron sobre los resultados utilizando pruebas en animales, $14,3 \%$ en un análisis comparativo entre los tratamientos tradicionales y el uso de piel de tilapia, y $21,4 \%$ sobre los mecanismos de composición y propiedades en relación con la piel humana. El uso de ensayos aleatorizados representó el 7,1\% de los artículos, el 28,6\% presentó los resultados en informes de casos y el 14,3\% explicó el desarrollo de la técnica hasta su importancia en los bancos de piel en la actualidad.

El estudio realizado en el Centro de Tratamiento de Quemaduras del Instituto Dr. José Frota, Hospital público de Fortaleza, Ceará, Brasil, seleccionó a 62 pacientes hospitalizados entre octubre de 2016 y septiembre de 2017, que fueron víctimas de quemaduras. Las variantes evaluadas fueron: el número de veces que hubo un intercambio del apósito oclusivo y los días para la cicatrización de la herida, el uso de analgésicos o anestésicos, la sensibilidad dolorosa, la mejoría de la quemadura en la extracción del apósito. El estudio analizó los datos y dividió a los participantes, 
desde: sexo, edad, agentes responsables del accidente, superficie corporal y segmentos quemados, y para ello, dividido en tres clasificaciones, A - pacientes ambulatorios con quemaduras de espesor superficial parcial inferior al 10\%, B pacientes hospitalizados con el mismo 10 a 20\%, C - pacientes hospitalizados con quemaduras profundas de espesor parcial del 5 al 15\%, y cada una de esta clasificación se dividió aleatoriamente en dos grupos de tratamiento: 48,4\% ( $n=30)$ Grupo de prueba que utilizó piel de tilapia como xenoinjerto y 51,6\% ( $n=32)$ Grupo de control: convencional con crema de sulfadiazina. El principal mecanismo de quemadura del Grupo de Prueba (clasificaciones A, B y C utilizando piel de tilapia como tratamiento) fue por líquidos calientes $56.25 \%(n=18)$. La intensidad del dolor fue menor en el grupo de prueba en comparación con el grupo de control. El número de apósitos requeridos durante el tratamiento, en el grupo de prueba fue menor, presentando 2,08 $\pm 0,28$ (A), 2,33 $\pm 0,71$ (B), 6,10 $\pm 2,02$ (C), mientras que en el grupo control 5,80 $\pm 0,42(A), 11,00 \pm 0,47$ (B), 20,20 $\pm 1,69$ (C) teniendo en cuenta el valor de $\mathrm{p}$ como 0,0001 . En cuanto al número de días para la reepitelización completa, el grupo de prueba presentó los mejores resultados, teniendo: 9,77 $\pm 0,83$ (A), 10,56 $\pm 1,13$ (B), 18,10 $\pm 0,99(C)$, mientras que el grupo control: $11,20 \pm 0,63$ (A), 11,70 $\pm 0,67$ (B), 21,30 $\pm 1,42$ C, considerando aproximadamente $P<0.0147$ (LIMA JUNIOR et al., 2020a)

Otro estudio realizado en el Centro de Tratamiento de Quemaduras en Fortaleza, Ceará, Brasil, seleccionó a 30 niños, entre 2 y 12 años, hospitalizados entre mayo de 2017 y marzo de 2018. Las variables utilizadas fueron: el total de días para la curación completa de la quemadura y el número de apósitos utilizados. Los pacientes se dividieron en dos grupos, en los que el $50 \%$ fueron ascendidos al grupo de prueba cutánea de tilapia y el resto al grupo de sulfadiazina de plata. El número promedio de días para completar la reepitelización fue de 10,47 $\pm 0,74$ en el grupo de sulfadiazina de plata y 10,07 $\pm 0,46$ en el grupo de piel de tilapia. La diferencia entre los dos grupos no fue estadísticamente significativa $(P=0,0868)$. El número de apósitos bajo anestesia realizados en pacientes tratados con piel de tilapia fue menor que los realizados en voluntarios tratados con sulfadiazina de plata. También se encontró una diferencia estadísticamente significativa para el número de apósitos 
sin anestésicos. Finalmente, el número total de apósitos se redujo significativamente en el grupo de piel de tilapia $(3,00 \pm 0,76)$ en comparación con el grupo de sulfadiazina de plata $(9,27 \pm 1,39)$ (LIMA JUNIOR et al., 2019a).

\section{DISCUSIÓN}

El estudio de las propiedades de la piel de la tilapia es un buen punto de partida para comprender su potencial de uso en quemaduras. Para esto, vale la pena analizar primero los hallazgos de Hu et al. (2017) que estudió el uso de un concentrado de polipéptido de colágeno extraído de la piel de tilapia, centrándose en su potencial curativo. Los ensayos in vitro utilizando células humanas preparadas mostraron que la adición de $50,0 \mu \mathrm{g} / \mathrm{ml}$ del concentrado al tejido lesionado trajo resultados estadísticamente significativos en relación con la velocidad de regeneración y reepitelización del tejido. Por otro lado, los estudios in vivo del mismo autor mostraron resultados prometedores con respecto a la curación por escaldado de espesor parcial profundo en los conejos probados. Los hallazgos fueron similares a los obtenidos con el apósito de hidrogel de colágeno, estudiado por Ge et al. (2020), por quemaduras profundas.

Además, se han realizado otros estudios para evaluar las propiedades de la piel del animal. Según Alves et al. (2015), la piel de tilapia presenta haces de fibras de colágeno densas, predominantemente tipo 1, con características microscópicas similares a las de la piel humana, así como alta resistencia a la tracción y extensión, lo que la hace prometedora como biomaterial en medicina regenerativa. El estudio de Ouyang et al. (2018) corrobora estos resultados, así como los de Hu et al. (2017), que también aborda la actividad antibacteriana del material y compromete su eficiencia de curado con otras soluciones disponibles en el mercado, obteniendo una alta eficiencia, además de proporcionar migración y proliferación celular.

Validado este potencial curativo de la piel de tilapia, es necesario comprender la usabilidad de este material en forma de apósitos biológicos. Según el estudio de Lima Junior (2017), la piel de tilapia tiene una adherencia considerable a las heridas por quemaduras en ratas de prueba, con resultados positivos durante la 
cicatrización, sin mutaciones significativas en los ámbitos bioquímico y hematológico de la función hepática y renal, constituyendo una posibilidad positiva como apósito biológico. Corroborando estos resultados, el ensayo clínico aleatorizado de Lima Junior et al. (2020c) mostró una buena adherencia en los pacientes, así como otras ventajas sobre otros apósitos, como el Aquacel $\mathrm{Ag}{ }^{\circledR}$, que se discutirá más adelante.

Dicho esto, vale la pena comparar la piel de la tilapia con otras soluciones existentes cuando se trata de quemaduras. Lima Junior et al. (2020c) y Marcelo y Brandt (2019) promovieron estudios que no muestran inferioridad en la piel de tilapia liofilizada, en comparación con el sórdido apósito de carboximetilcelulosa impregnado de plata, Aquacel Ag ${ }^{\circledR}$. El estudio de Lima Junior et al. (2020c) enfatiza que el uso de piel de tilapia ofrece una mejora subjetiva en la cantidad de dolor reportado y el número de apósitos requeridos, reduciendo así el costo del tratamiento y la carga de trabajo del equipo. Por lo tanto, la piel de tilapia es una buena opción para el tratamiento de quemaduras.

\section{CONCLUSIÓN}

En vista de los hallazgos de la literatura reportada en la presente revisión, se concluye que los estudios con la piel de tilapia del Nilo, peces de agua dulce, realizados por investigadores de la Universidad Federal de Ceará, quienes fueron, desde 2016, los pioneros en patentar el método. Además, ha sido una modalidad revolucionaria con numerosos beneficios en el tratamiento de pacientes con lesiones superficiales y profundas de la piel expandiéndose a varias áreas de la medicina, probadas en medicina veterinaria, dentro y fuera del país (LIMA JUNIOR, 2017).

Con base en los registros de la investigación, se refuerzan los beneficios del uso de la piel de tilapia en el tratamiento de quemaduras, considerando que ofrece una reducción del dolor del paciente debido al período más largo adherido a la piel del paciente. Además del reducido poder de infección y contaminación, la alta resistencia debido a la gran cantidad de colágeno presente en la piel de pescado, lo que resulta en una buena estética y bajo costo, en comparación con otras formas de tratamiento. 
Por ello, los investigadores llegaron a la conclusión, respondiendo a la pregunta guía, de que el nuevo método es, eso sí, un avance importante en el tratamiento de quemaduras, pues se confirma su empleabilidad, además de demostrar una ventaja sobre algunas de las principales alternativas preexistentes.

\section{REFERENCIAS}

ALVES, Ana; VERDE, Maria; FERREIRA FILHO, Antônio; SILVA, Paulo; FEITOSA, Victor; LIMA JUNIOR, Edmar; MIRANDA, Marcelo; MORAES FILHO, Manoel. Avaliação microscópica, estudo histoquímico e análise de propriedades tensiométricas da pele de tilápia do Nilo. Revista Brasileira de Queimaduras, v. 14, n. 3, p. 203-210, 2015.

COSTA, Bruno; LIMA JÚNIOR, Edmar; MORAES FILHO, Manoel; FECHINE, Francisco; MORAES, Maria; SILVA JUNIOR, Francisco; SOARES, Maria; ROCHA, Marina. Use of Tilapia Skin as a Xenograft for Pediatric Burn Treatment: A Case Report. Journal of Burn Care \& Research, v. 40, n. 5, p. 714-717, 2019.

GE, Baosheng; WANG, Haonan; LI, Jie; LIU, Hengheng; YIN, Yonghao; ZHANG, Naili; QIN, Song. Comprehensive Assessment of Nile Tilapia Skin (Oreochromis niloticus) Collagen Hydrogels for Wound Dressings. Marine Drugs, v. 18, n. 4, p. $178,2020$.

HU, Zhang; YANG, Ping; ZHOU, Chunxia; LI, Sidong; HONG, Pengzhi. Marine Collagen Peptides from the Skin of Nile Tilapia (Oreochromis niloticus): Characterization and Wound Healing Evaluation. Marine Drugs, v. 15, n. 4, p. 102, 2017.

LEONTSINIS, Cybele; LIMA JUNIOR, Edmar; MORAIS FILHO, Manoel; BRITO, Maria; ROCHA, Marina; NASCIMENTO, Maria; SILVA JUNIOR, Francisco; MIRANDA, Marcelo. Elaboração de um protocolo para implementação e funcionamento do primeiro banco de pele animal do Brasil: Relato de experiência. Revista Brasileira de Queimaduras, v. 17, n. 1, p. 66-71, 2018. 
LIMA JUNIOR, Edmar; PICOLLO, Nelson; MIRANDA, Marcelo; RIBEIRO, Wesley; ALVES, Ana; FERREIRA, Guilherme; PARENTE, Ezequiel, MORAES FILHO, Manoel. Uso da pele de tilápia (Oreochromis niloticus), como curativo biológico oclusivo, no tratamento de queimaduras. Revista Brasileira de Queimaduras, v. 16, n. 1 , p. 10-17, 2017.

LIMA JÚNIOR, Edmar. Tecnologias inovadoras: uso da pele da tilápia do Nilo no tratamento de queimaduras e feridas. Revista Brasileira de Queimaduras, v. 16, n. 1, p. 1-2, 2017.

LIMA JÚNIOR, Edmar; MORAES FILHO, Manoel; FORTE, Antônio; COSTA, Bruno; ; FECHINE, Francisco; ALVES, Ana; MORAES, Maria; ROCHA, Marina; SILVA JUNIOR, Francisco; SOARES, Maria; BEZERRA, Alane; MARTINS, Camila; MATHOR, Mônica. Pediatric Burn Treatment Using Tilapia Skin as a Xenograft for Superficial Partial-Thickness Wounds: A Pilot Study. Journal of Burn Care \& Research, 2019a.

LIMA JUNIOR, Edmar; MORAES FILHO, Manoel; COSTA, Bruno Almeida; FECHINE, Francisco; MORAES, Maria; SILVA JUNIOR, Francisco; SOARES, MARIA; ROCHA, MARINA, LEONTSINIS, Cybele. Innovative treatment using tilapia skin as a xenograft for partial thickness burns after a gunpowder explosion. Journal of Surgical Case Reports, v. 2019, n. 6, $2019 \mathrm{~b}$.

LIMA JÚNIOR, Edmar; MORAES FILHO, Manoel; COSTA, Bruno; ROHLEDER, Andréa; ROCHA, Marina; FECHINE, Francisco; FORTE, Antonio. ALVES, Ana, SILVA JUNIOR, Francisco; MARINS, Camila; MATHOR, Mônica; MORAES, Maria. Innovative Burn Treatment Using Tilapia Skin as a Xenograft: A Phase II Randomized Controlled Trial. Journal of Burn Care \& Research, v. 41, n. 3, p. 585592, 2020a.

LIMA JUNIOR, Edmar; MORAES, Manoel Odorico; COSTA, Bruno Almeida; UCHÔA, Alex; MARTINS, Camila; MORAES, Maria; ROCHA, Marina; FECHINE, Rodrigo. Treatment of deep second-degree burns on the abdomen, 
thighs, and genitalia: use of tilapia skin as a xenograft. Revista Brasileira de Cirurgia Plástica (RBCP) - Brazilian Journal of Plastic Sugery, v. 35, n. 2, p. 243-248, 2020b.

LIMA JÚNIOR, Edmar; MORAES FILHO, Manoel ; COSTA, Bruno Almeida; FECHINE, Francisco; ROCHA, Marina; VALE, Mariana; DIÓGENES, Ana; UCHÔA, Alex; SILVA JUNIOR, Francisco; MARTINS, Camila; BANDEIRA, Tereza; RODRIGUES, Felipe; PAIER, Carlos; MORAES, Maria. A Randomized Comparison Study of Lyophilized Nile Tilapia Skin and Silver-Impregnated Sodium Carboxymethylcellulose for the Treatment of Superficial Partial-Thickness Burns. Journal of Burn Care \& Research, v. 42, n. 1, p. 41-48, 2020 c.

DE MIRANDA, Marcelo José Borges; BRANDT, Carlos Teixeira. Xenoenxerto (pele da Tilápia-do-Nilo) e hidrofibra com prata no tratamento das queimaduras de II grau em adultos. Rev. bras. cir. plást, p. 79-85, 2019.

OUYANG, Qian-Qian; HU, Zhang; LIN, Zhen-Peng; QUAN, Wei-Yan; DENG, YiFeng; LI, Si-Dong; LI, Pu-Wang, CHEN, Yu. Chitosan hydrogel in combination with marine peptides from tilapia for burns healing. International Journal of Biological Macromolecules, v. 112, p. 1191-1198, 2018.

Enviado: Julio de 2021.

Aprobado: Diciembre de 2021. 